\title{
PHYSIOLOGICAL ORGANIZATION OF LAYER 4 IN MACAQUE STRIATE CORTEX ${ }^{1}$
}

\author{
GARY G. BLASDEL ${ }^{2}$ AND DAVID FITZPATRICK ${ }^{3}$ \\ Departmenis of Anatomy and Ophthalmology, Medical University of South Carolina, Charleston, South Carolina 29425
}

Received July 8, 1983; Revised October 7, 1983; Accepted October 14, 1983

\begin{abstract}
Numerous highly angled electrode penetrations through the opercular region of macaque striate cortex reveal that layers $4 \mathrm{~A}, 4 \mathrm{C} \alpha$, and $4 \mathrm{C} \beta$-the primary input sublaminae for axons from the lateral geniculate nucleus (LGN) - are retinotopically organized on a fine scale and populated mostly by monocularly driven cells having small receptive fields and lacking orientation selectivity. Layer $4 \mathrm{~B}$, which does not receive a direct thalamic input, contains orientationally selective cells, and many of these are also direction selective. To a significant degree the response properties of cells in layers $4 \mathrm{C} \alpha$ and $4 \mathrm{C} \beta$ reflect the response properties of their respective afferent inputs, from the magnoand parvocellular laminae of the LGN. Accordingly, cells in layer $4 \mathrm{C} \alpha$ have lower contrast thresholds and larger minimum response fields than do the cells in layer $4 \mathrm{C} \beta$. In contrast to this clear-cut separation, the cells of layer 4A (whose major source of direct LGN input arises from the parvocellular layers) exhibit both high and low contrast thresholds. With regard to the precision of retinotopic mapping that is seen in lamina $4 \mathrm{C}$, it is noteworthy that there is substantial overlap among the minimum response fields of neighboring neurons. Due to a larger mean receptive field size, this overlap is greater in layer $4 \mathrm{C} \alpha$ than it is in $4 \mathrm{C} \beta$. In either sublamina, however, the minimum cortical distance that separates different and nonoverlapping parts of the visual field corresponds closely - within a factor of 2 - to the known arborizational spreads of single geniculate afferents.
\end{abstract}

In primates the vast majority of geniculocortical afferents terminate in layer 4 of striate cortex-an arrangement which ensures that most visual information passes through this lamina before becoming available to other cortical cells. As a consequence, most cells in layer 4 do not exhibit the orientation selectivity and binocularity that one normally associates with striate cortical neurons, and they have distinctly small receptive fields. These fields are approximately the same size as those of cells in the lateral geniculate nucleus (LGN). Furthermore, whereas geniculorecipient layer 4 neurons outnumber LGN neurons many times over, each one also receives

\footnotetext{
' This research was supported by Grants EY-03321 and EY04064 from the National Eye Institute and by South Carolina State Appropriated Funds. We thank Jennifer Lund for generous support and encouragement, and David Hubel for helpful comments on the manuscript. We are also grateful to Kathryn Cowart and Kathy Ludden for technical assistance, and to Diane Ashworth for secretarial assistance.

${ }^{2}$ To whom correspondence should be sent, at his present address: Department of Neurology, University of Pittsburgh, Room 337, Scaife Hall, Terrace and Desoto Streets, Pittsburgh, PA 15261.

${ }^{3}$ Present address: Department of Anatomy, Duke University Medi-
} cal Center, Durham, NC 27706. a strongly convergent input, from several LGN fibers. Therefore, it may be said that visual information diverges and converges during its passage through layer 4 and, in the process, becomes reorganized. Due to the location of this reorganization-at the interface between the LGN and striate cortex - the transformations that occur assume a particular significance.

From previous anatomical and physiological reports it is apparent that the geniculorecipient zones of layer 4layers $4 \mathrm{~A}, 4 \mathrm{C} \alpha$, and $4 \mathrm{C} \beta$ in the macaque monkeyreceive their afferent input from separate populations of geniculate neurons (Hubel and Wiesel, 1972; Hendrickson et al., 1978; Blasdel and Lund, 1983). Axons arborizing in layers $4 \mathrm{~A}$ and $4 \mathrm{C} \beta$ originate in the parvocellular division of the $L G N$, and afferents to layer $4 \mathrm{C} \alpha$ originate in the magnocellular division. Even though both sets of afferents must cover correspondingly large areas-layers $4 \mathrm{C} \alpha$ and $4 \mathrm{C} \beta$ being roughly coextensive - they arise from vastly different numbers of geniculate neurons. There are roughly 6 times as many parvocellular neurons as there are magnocellular ones. In compensation for this numerical imbalance, magnocellular afferents arborize farther than parvocellular ones and cover 6 times as much area (Blasdel and Lund, 1983). 
These morphological differences in the arborization of magno- and parvocellular LGN neurons are matched by differences in their physiological responses (Wiesel and Hubel, 1966; Dreher et al., 1976; Schiller and Malpeli, 1978; Lee et al., 1979; Shapley et al., 1981; Lennie and Derrington, 1982). The more numerous parvocellular neurons, for example, are the only ones to have color opponent receptive fields, and their receptive fields tend to be quite small. Magnocellular neurons, on the other hand, exhibit broad band responses (to all visual wavelengths) and large receptive fields (Sherman et al., 1976). However, the most striking difference between these two sets of neurons revolves about the fact that magnocellular neurons are about 10 times more sensitive than parvocellular neurons to visual stimuli having low luminance contrast.

If we think of neurons in the parvo- and the magnocellular LGN laminae as conveying two separate and complementary representations of the visual world, it is intriguing that their terminations in layer $4 \mathrm{C}$ should end in such close proximity to one another-in layers $4 \mathrm{C} \alpha$ and $4 \mathrm{C} \beta$ and yet still remain separate. From the anatomical studies of Lund (1973) and others we know that layer $4 \mathrm{C}$ is populated by a highly specialized type of spiny stellate cell with circumscribed dendritic arborizations. The vertical extent of these arborizations is small so that cells lying in layer $4 \mathrm{C} \alpha$ are contacted primarily by magnocellular afferents and cells lying in layer $4 \mathrm{C} \beta$ are contacted primarily by parvocellular afferents. In contrast to the arborizational patterns of their afferent inputs, though, the postsynaptic dendrites in $4 \mathrm{C} \alpha$ and $4 \mathrm{C} \beta$ have similar amounts of lateral spread and rarely extend farther than 180 to $200 \mu \mathrm{m}$.

The general response properties of layer 4 neurons are best known from the pioneering studies of Hubel and Wiesel $(1968,1977)$, who reported that the cells of lamina $4 \mathrm{C}$ have small receptive fields, lack orientational selectivity, and respond exclusively to the visual stimulation of one eye. One particularly fascinating aspect of lamina $4 \mathrm{C}$ organization concerns the presence of very precise and well defined retinotopic maps that may be discerned within the dimensions of single ocular dominance columns (Hubel et al., 1974).

Given the pronounced segregation of magno- and parvocellular afferents that is known to occur in lamina $4 \mathrm{C}$, it would be reasonable to expect some preservation of magnocellular-like responses in layer $4 \mathrm{C} \alpha$ and parvocellular-like responses in layer $4 \mathrm{C} \beta$. Furthermore, faced with the very different spreads of individual afferent arbors, it is hard to imagine that the retinotopic maps in layers $4 \mathrm{C} \alpha$ and $4 \mathrm{C} \beta$ do not somehow differ. The answers to these questions are not available from previous work. Hubel and Wiesel $(1968,1977)$ did not distinguish between the physiological responses of cells in layers $4 \mathrm{C} \alpha$ and $4 \mathrm{C} \beta$; and more recent investigators (Bullier and Henry, 1980; Mitzdorf and Singer, 1979) who made this distinction have concentrated on phenomena, such as conduction velocity, that relate more directly to the properties of afferent thalamic axons than to the properties of cells lying postsynaptic.

In an effort to examine these issues we have made a number of highly tangential electrode penetrations through layer 4 in the opercular region of macaque striate cortex. By making many discrete lesions during the course of each penetration we have been able to correlate measurements of receptive field size and contrast sensitivity with particular subdivisions of layer 4 . We have also been able to verify that a relatively precise retinotopic organization exists in both subdivisions of layer $4 \mathrm{C}$ and, to some extent, even in $4 \mathrm{~A}$. Our recordings, together with previously obtained data on the dendritic fields of layer 4 neurons (Lund, 1973) and the axonal fields of LGN afferents (Blasdel and Lund, 1983), suggest a close relationship between the retinotopic organization of cells in layer 4 and the reported patterns of axonal and dendritic arborization. These results have been reported briefly (Blasdel and Lund, 1982; Blasdel et al., 1983).

\section{Materials and Methods}

Physiology. We relied on previously reported procedures (Blasdel and Lund, 1983) in our surgical preparation of six macaque monkeys (two Macaca nemestrina; four $M$. fascicularis). Each animal was quickly intubated, after being induced with ketamine, and then maintained on a mixture of nitrous oxide and oxygen with enough halothane added to ensure surgical stability. A 25 gauge butterfly needle was inserted into the cephalic vein and taped into position. The animal's head was then secured in a modified Horseley-Clark head holder that allowed a calibrated rotation about the interaural line. A $60^{\circ}$ forward tilt of the animal's head was found to greatly facilitate visualization of the occipital pole and placement of the recording electrodes.

Most of our recordings were obtained from the outer opercular surface of striate cortex, approximately $8 \mathrm{~mm}$ from the midline, in a region that corresponds to the horizontal meridian at an eccentricity of 5 to $8^{\circ}$. After a small craniotomy had been drilled and a dural flap reflected, we introduced the guide tube of our microdrive to the opening so that the tip came to rest less than 0.5 $\mathrm{mm}$ above the pial surface. The craniotomy was then filled with warm agar (3\% in saline) and sealed with a low melting point wax. After all potentially traumatic surgical procedures had been completed, we discontinued the use of halothane and relied on nitrous oxide, supplemented with Pentothal $(0.5$ to $2.0 \mathrm{mg} / \mathrm{kg} / \mathrm{hr})$ to maintain anesthesia. The animal was then paralyzed with pancuronium bromide $(0.1 \mathrm{mg} / \mathrm{kg})$ in a dextrose and salt maintenance solution. When our recordings approached a critical point (e.g., when our electrode began to isolate the small nonoriented units characteristic of layer $4 \mathrm{C}$ ), we administered additional, supplemental doses $(0.05$ $\mathrm{mg} / \mathrm{kg}$ ) of pancuronium every $0.5 \mathrm{hr}$. Incisions and pressure points were infiltrated with a long-acting local anesthetic (Marcaine Hydrochloride) and the corneae were anesthetized with Ophthetic.

We used glass-insulated platinum iridium microelectrodes (Wolbarsht et al., 1960) to isolate cells and to make small electrolytic lesions during the course of each electrode penetration. The electrode was advanced by a microprocessor-controlled stepping motor microdrive (Central Engineering Services, California Institute of Technology) which, due to a very rapid rate of advancement, avoids problems associated with tissue adhesion 

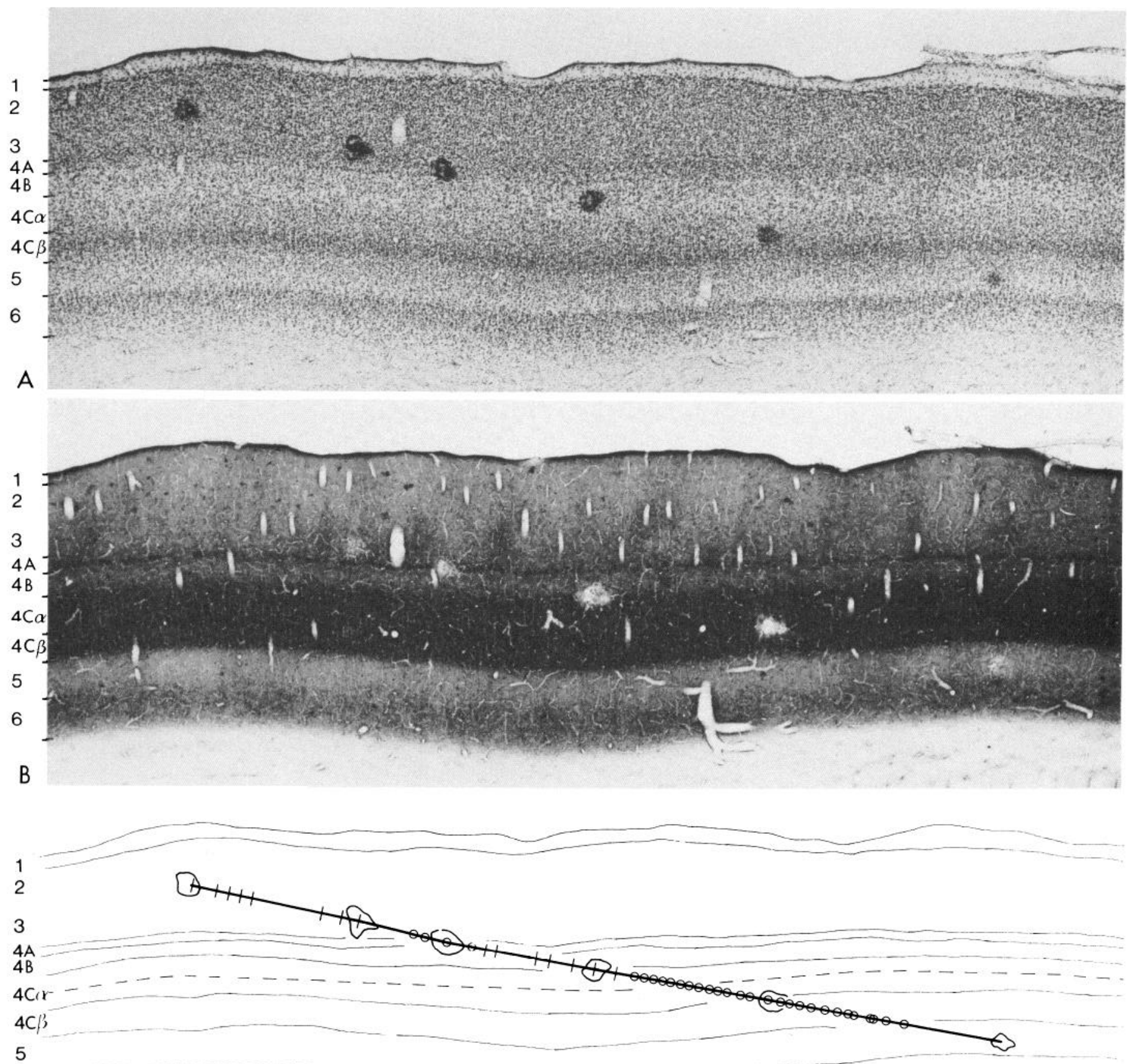

6

C

Figure 1. $A$ and $B$, In the top photomicrograph $(A)$ a $40-\mu$ m section through one electrode track has been stained with thionin for Nissl substance. The middle photomicrograph $(B)$ has been reacted for cytochrome oxidase. The electrode penetration that was made through this part of the cortex occurred at an angle of $7^{\circ}$ with respect to the cortical surface and was punctuated with six electrolytic lesions which appear in the above material as dark and light spots. The entire track is reconstructed in $C$, where orientationally selective units appear as lines and nonoriented ones appear as circles. By comparing the elevation of the third lesion in the Nissl and cytochrome material it becomes apparent that the thin cytochrome-rich band lies just above the single line of cells that previously has been used to define lamina 4A (Lund, 1973), in agreement with the observations of Hubel and Wiesel (1972). Accordingly, we use the upper boundary of the cytochrome band and the lower boundary of the Nissl band to define lamina 4A. Following a similar line of reasoning, if one compares the elevation of the fourth lesion in the two sets of material, one sees that the upper boundary of the thick cytochrome-rich band actually lies above the upper boundary of layer $4 \mathrm{C}$ (as previously defined on the basis of Nissl material). Since previous studies have indicated that the cytochrome-rich band corresponds to the zone of thalamic afferents (Hubel and Livingston, 1981; Blasdel and Lund, 1983; Fitzpatrick et al., 1983), we use this label to define the upper and lower limits of lamina 4C. $C$, During the course of this electrode penetration (indicated by the sequence of lesions) we recorded from 46 units. Thirty-one of these lacked orientation selectivity and were recorded either 
and dimpling. In order to minimize errors that might result from residual eye movements (see below), we always made our electrode penetrations in the sagittal plane so that the electrode tip traversed the visual field in a nearly vertical direction. The penetration was angled in such a way that each electrode followed a highly tangential trajectory, dwelling for large distances in cortex that had not been disturbed by the removal of overlying bone and dura. To aid in electrode track reconstruction, we made small electrolytic lesions at regular intervals (as well as at points of special interest) by passing 3 $\mu \mathrm{A}$ of cathodal current for $4 \mathrm{sec}$.

Visual stimulation. After the animal's eyes had been cyclopleged and dilated with homatropine we used a slit retinoscope to determine the radius of hard contact lens curvature needed to make the animal emmetropic at 2 $\mathrm{m}$. The animal was then provided with a pair of $3-\mathrm{mm}$ artificial pupils, which we placed in front of the contact lenses so that they were centered over the optical axis of each eye.

At the beginning of each penetration we used a handheld projector to map receptive filed positions for each eye. We then adjusted the position of the animal's head relative to a color video monitor ${ }^{4}$ such that each eye's visual receptive field was brought into correspondence with the center of the screen. The latter adjustments in azimuth and elevation were made by moving the cart and by adjusting the tilt of the animal's head. In general, this alignment was required only once for any given electrode penetration.

Receptive field analysis. Every unit that we encountered was studied first with a small dark or light bar (or spot) and mapped according to established procedures

\footnotetext{
${ }^{4}$ For visual stimulation we used a video image processor in conjunction with an ISI-11/23 computer to manipulate the images created by two $512 \times 512$ bit planes on the screen of an ultra-high resolution color monitor (Mitsubishi C-3910). We used one bit plane to present "conventional" visual stimuli (e.g., bars and spots) under the control of either a joystick or the computer. We used the other bit plane as a "scratch pad" to record the positions of receptive field limits (Barlow et al., 1967; Blasdel and Lund, 1983) and boundaries, ON and OFF zones, etc. Once these markings had been refined to the point where they accurately reflected a unit's receptive field, they were stored on disk, together with a description of other salient properites, so that they could be retrieved for later analysis. The actual values specified by each two-bit pixel were interpreted through a 24-bit color lookup table-an arrangement that allows 256 grey levels for each color phosphor. Due to the fact that the luminance of each phosphor changes as an independent, nonlinear function of the input voltage, each of the three color signals required calibration. This was accomplished with the aid of a photopically corrected photodiode (United Detector Technology, PIN-10AP) connected through a current amplifier to one A/D channel of the computer. A $200-\mathrm{mm}$ Nikon lens was used to bring the photodiode into correspondence with a $1^{\circ}$ spot on the monitor screen. (Preliminary measurements confirmed that luminance changes little (less than $1 \%$ ) with adjustments in raster size or position.) This arrangement allowed the computer to automatically calibrate the system by generating a luminance/voltage lookup table.
}

(e.g., Nonoriented, Simple, Complex, Hypercomplex, etc.; Hubel and Wiesel, 1962, 1977; Barlow et al., 1967). After the ocular dominance had been determined we concentrated our further efforts on the receptive field of the dominant eye. If the unit was found to be orientationally selective, we determined the orientational limits (Blasdel et al., 1977). Nonoriented units were distinguished from orientationally biased ones on the basis of the ratio of their responses to optimally and least optimally oriented stimuli. If this ratio exceeded two, the unit was considered orientationally selective. Binocular units lacking orientation selectivity were never observed. Once the optimal slit orientation, width, length, and contrast preference (i.e., for light or for dark stimuli) had been established, we determined the limits of the minimium response field (Barlow et al., 1967). Since our subsequent measurements of receptive field size depended entirely on these limits, a brief description of their determination is in order.

For a unit that has been determined to be orientationally selective, we first move an optimally oriented slit across the receptive field a number of times while gradually displacing it to one side. As the end of the slit begins to exit the receptive field, the unit stops responding. By noting the position of the slit edge at the time that the unit stops responding, it is possible to define one limit of the minimum response field. Similar determinations can be made for each of the remaining flanks. For some Simple cells we found that it was necessary to map different parts of the receptive field with dark as well as with light stimuli. Since the direction of slit movement does not matter to units lacking orientation selectivity, nonoriented cells were always mapped with small slits moving orthogonally to the edge of the limit under consideration. Eight separate determinations, set at the edges of an imaginary octagon, usually sufficed to define the receptive field limits of a nonoriented cell. Since this technique relies on responses to stimuli moving at optimal speeds, it avoids errors associated with differences in response latency, speed of stimulus movement, etc. Accordingly, the limits that we determine accurately reflect boundaries within which the presence of an edge will trigger a response. Although it is conceivable that more elaborate mapping techniques might show regions outside these limits where the cell's firing can be influenced, we believe the edge-sensitive zone that we measure to be the most relevant and accessible.

We determined contrast threshold against a broad band background luminance of $3 \mathrm{~cd} / \mathrm{mm}^{2}$. If a unit displayed orientational selectivity, we determined this threshold by slowly adjusting the luminance of a moving or flashing, broad band bar, whose orientation, length, width, and direction of movement had already been optimized, above and below background, to the point where the unit first began to respond. For nonoriented units, the procedure was similar, except that we used a small square or spot whose dimensions coincided with

from layer $4 \mathrm{~A}$ or from layer $4 \mathrm{C}$. From this reconstruction it is evident that nonoriented units encountered soon after the electrode tip penetrated the cytochrome-rich zone that we use to define lamina $4 \mathrm{C}$. Isolated units lacking orientational selectivity appeared shortly thereafter. This is not a consistent result, although as may be surmised from Figures 2 and 3 . It may be said, however, as the results of Figures 2 and 3 indicate, that even though this transition zone occurs at variable depths relative to the cytochromerich band of lamina $4 \mathrm{C}$, that it always occurs abruptly and therefore indicates a zone which is functionally discrete. 

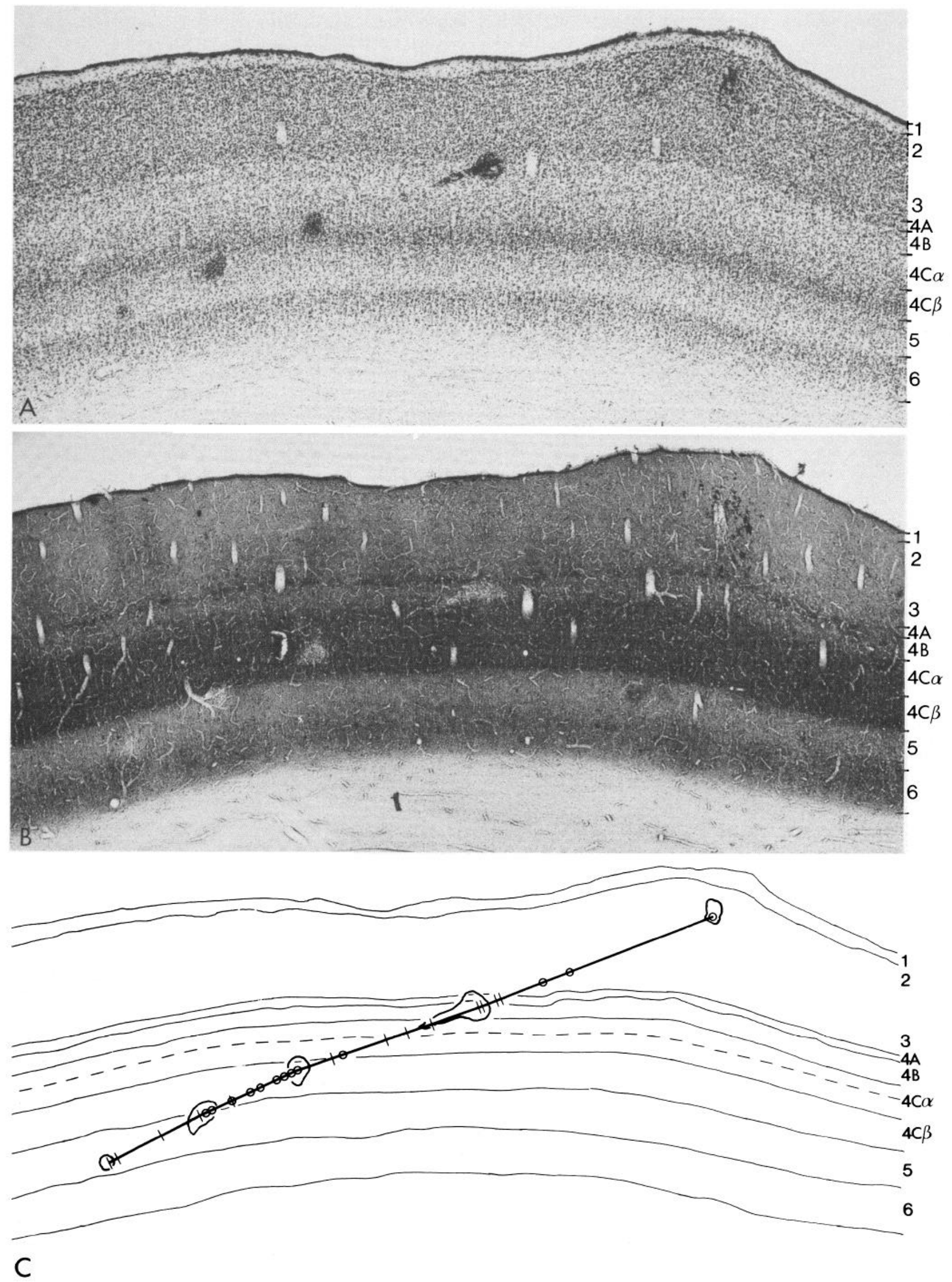

Figure 2 
those of the receptive field center. Although this technique differs from those used by others (Lennie and Derrington, 1981; Shapley et al., 1981), which generally rely on drifting sine wave gratings, the results are comparable. For reasons associated mostly with the geometry and temporal aspects of each visual pattern, our technique produces measurements of contrast threshold that are approximately three times higher than those produced with drifting gratings (see Blasdel and Lund (1983), for further discussion). In addition, our technique has the advantage of working with many cortical cells that do not respond well to drifting sine wave gratings.

Control for eye movements. Studies entailing the high resolution analysis of visual receptive field maps are subject to errors induced by eye movement. Due to the seriousness of this problem several strategies have evolved for dealing with it, the most elegant of which is probably the reference cell technique of Hubel and Wiesel (1973). Due to the complexity of this and other techiques, however, we have opted for a simpler approach which entails (1) reducing eye movements to an absolute minimum, and (2) structuring measurements of receptive field position in such a way that any residual errors are of little consequence.

Due to our use of a potent competitive inhibitor of acetylcholine (pancuronium bromide) to achieve paralysis, as opposed to the depolarizing blockers used by others (Hubel and Wiesel, 1962), residual eye movements, to begin with, are mininal. Preliminary experiments in which we remapped the receptive field of a single unit many times over a period of several hours revealed that these movements consist for the most part of small, lateral, and transient deviations. The movements are usually no more than $0.25^{\circ}$ (never more than $0.5^{\circ}$ ) and generally last no longer than 3 to $5 \mathrm{sec}$, after which time the eyes return to their resting fixation. Superimposed on these small transient deviations, there is an additional, gradual decrease in the elevation of the visual axis that proceeds at a rate of approximately $1 \% / 24$-hr period-a rate that presents minimal complications during the 2 to $3 \mathrm{hr}$ we spend mapping the positions of cells in layer $4 \mathrm{C}$. As noted earlier, our animals received supplemental doses of pancuronium at times when it was considered especially important that the eyes remain stable. In an effort to minimize the consequences of the small, residual, lateral deviations, we angled our electrodes so that they traversed the representation of the horizontal meridian in an anterior to posterior direction-a tactic which had the effect of confining retinotopic changes of interest to shifts in elevation. We also mapped each receptive field repetitively, over a period of several minutes. Finally, it should be noted that errors associated with spurious eye movements are random, and random components can only make it more difficult to see a pattern of orderliness in the receptive field positions of sequentially recorded cells.

Histology. Following the administration of a lethal dose of Nembutal, the animals were perfused through the heart with 0.5 to 1 liter of a phosphate-buffered saline solution (containing $0.5 \%$ sodium nitrite), followed by 2 liters of fixative which contained $2 \%$ paraformaldehyde and $1 \%$ glutaraldehyde in $0.1 \mathrm{M}$ phosphate buffer $(\mathrm{pH}$ 7.4). After the fixative had been washed out with a $10 \%$ sucrose buffer rinse, the cranium over the occipital lobe was removed and the head was positioned in a stereotaxic holder to permit blocking of the relevant portions of striate cortex. Pieces of striate cortex containing the electrode tracks were placed in a $30 \%$ sucrose buffer solution and kept in the refrigerator until they sank. The tissue was then sectioned at $30 \mu \mathrm{m}$ on a freezing microtome and collected in $0.1 \mathrm{M}$ phosphate buffer. One set of alternate sections was processed for cytochrome oxidase histochemistry, using the protocol suggested by WongRiley (1979) while the other set was mounted and stained with thionin.

\section{Results}

Laminar boundaries. Previous physiological studies of macaque striate cortex have relied on the distribution of cell bodies, as revealed by a Nissl stain, to define laminar borders and assess the location of recording sites (Hubel and Wiesel, 1968; Dow, 1974; Gouras, 1974; Schiller et al., 1976; Bullier and Henry, 1980). In the present report we have employed both Nissl-stained sections and sections which have been reacted to show the distribution of the mitochondrial enzyme cytochrome oxidase to define laminar boundaries. The distribution of cytochrome oxidase provides a valuable adjunct to Nissl staining criteria since it can be used to demarcate accurately the locations of geniculate terminations (Horton and Hubel, 1981; Hubel and Livingstone, 1981; Blasdel and Lund, 1983; Fitzpatrick et al., 1983). Knowing the location and the extent of geniculate terminal zones aids in identifying the subdivisions of lamina 4 as defined by Lund (1973), since some of these have no clear-cut Nissl correlates.

In Figure 1 ( $A$ and $B$ ) we compare the patterns of cytochrome oxidase and Nissl staining in two adjacent sections of striate cortex that were taken from the region of an electrode track, where six marking lesions had been made. The lesions appear as dark spots in the Nissl material and as light spots in the cytochrome oxidase material. Since they mark identical positions in both sections, these lesions make it possible to accurately compare laminar boundaries seen by cytochrome oxidase staining with those that are evident from the Nissl stain. For example, it is evident from the elevation of the third lesion (from the left) that the thin band of cytochrome oxidase activity in lamina $4 \mathrm{~A}$ (that presumably corresponds to the zone of geniculate input) actually lies just above the thin line of cells that defines lamina $4 \mathrm{~A}$ in the Nissl material (Lund, 1973), in agreement with previous observations (Hubel and Wiesel, 1972).

The pattern of cytochrome oxidase staining shown in

Figure 2. This figure shows a reconstruction electrode penetration that we made at an angle of $20^{\circ}$ with respect to the cortical surface. During the course of this penetration we recorded from 26 units and made five lesions. As in Figure 1, the lesions appear in the Nissl and cytochrome oxidase material as dark and light spots, respectively. Unlike the penetration shown in Figure 1, however, this electrode penetration included recordings from four orientationally selective units that clearly resided in layer $4 \mathrm{C} \alpha$. An unbroken sequence of nonoriented units was not encountered until the electrode tip had penetrated layer $4 \mathrm{C} \beta$. 
Figure 1 resembles that found by other investigators and consists of a prominent wide band of intense staining separated from a thin band by a region devoid of staining. We define lamina 4 as extending from the dorsal border of the thin strip of intense cytochrome activity to the base of the wide strip. Within this zone we identify lamina $4 \mathrm{~A}$ as the thin strip of intense cytochrome activity plus a thin band of small cells which is visible in the Nissl material and which lies just below. Lamina $4 \mathrm{~B}$ is distinguished in the Nissl stain by the presence of conspicuously large somata and in the cytochrome material by its pale staining quality. Lamina $4 \mathrm{C}$ we take to coincide with the wide band of intense cytochrome staining. This lamina may be further subdivided into a lower cellrich half $(4 \mathrm{C} \beta)$ which receives parvocellular geniculate axons and a less densely packed upper half $(4 \mathrm{C} \alpha)$ which receives magnocellular geniculate axons (Hubel and Wiesel, 1972; Hendrickson et al., 1978; Blasdel and Lund, 1983; Fitzpatrick et al., 1983).

We should point out that the border between layers $4 \mathrm{C} \alpha$ and $4 \mathrm{~B}$, as drawn here, is higher than the level usually taken as this boundary on the basis of Nissl staining alone (Lund, 1973). Since we know from previous work that magnocellular afferents extend to the upper limit of the cytochrome-rich region (Blasdel and Lund, 1983), we have chosen for simplicity to define layer $4 \mathrm{~B}$ as the zone devoid of geniculate terminations. This allows us to use the cytochrome border to delimit layer $4 \mathrm{C} \alpha$ from $4 \mathrm{~B}$. The arbitrary nature of this definition should be kept in mind, however, since the intrinsic circuitry of striate cortex may have its own laminar subdivisions, and these may not be tied rigidly to the pattern of geniculate inputs.

Receptive field organization (oriented versus nonoriented) and relation to laminar borders. In normal macaque striate cortex there are many monocularly driven neurons with small receptive fields that respond to all orientations of visual stimulation (Hubel and Wiesel, 1968). Hubel and Livingstone (1981; Livingstone and Hubel, 1984) have recently shown that some of these appear in the cytochrome patches of layer 3 . The great majority, however, appear clustered somewhat deeper in layer 4 , and in the present experiments we have tried to associate them with particular subdivisions of this lamina. On the basis of 446 units recorded during the course of 13 electrode penetrations (in six macaque monkeys) we observe a sequence that begins in uppermost layer 4 with (1) the appearance of a short stretch of non-oriented units followed by (2) a responsive group of orientationally selective and occasionally binocular Simple and Complex cells followed by (3) a sequence of monocular and non-oriented cells which eventually is followed by (4) a group of highly binocular complex cells with large receptive fields.

This sequence appears clearly in the electrode track reconstructions of Figures 1, 2, 4, and 5 . In each case the first cluster of nonoriented cells appears in close juxtaposition to layer $4 \mathrm{~A}$. The second sequence of nonoriented units begins after the electrode tip enters layer $4 \mathrm{C}$; and this sequence persists, uninterrupted by oriented ones, until the electrode tip passes out of layer $4 \mathrm{C} \beta$ and into layer 5 .
In Figure 1 the second sequence of non-oriented cells appears just below the transition between layers $4 \mathrm{~B}$ and $4 \mathrm{C} \alpha$. In Figure 2, however, the second sequence does not appear until after the electrode tip has entered lower layer $4 \mathrm{C} \beta$. In layer $4 \mathrm{C} \alpha$ we found oriented Simple and Complex cells. Accordingly, one might surmise that the demarcation between oriented and non-oriented units, although abrupt, does not always occur in rigid association with the $4 \beta-4 \mathrm{C} \alpha$ border as defined by cytochrome oxidase staining. The notion of variability is further enhanced by the penetration illustrated in Figure 3 where, due to the extreme inclination of our electrode tip, we traversed upper layer $4 \mathrm{C} \alpha$ for several millimeters. During this traverse we recorded from clusters of both oriented and nonoriented units. Since the electrode never entered layer $4 \mathrm{C} \beta$, it appears that the transition zone between oriented and nonoriented units may vary within layer $4 \mathrm{C} \alpha$. Such a variation could explain variability in the literature concerning the presence and abundance of nonoriented cells in lamina $4 \mathrm{C} \alpha$ (Bullier and Henry, 1980; Livingstone and Hubel, 1984). On the other hand, in layer $4 \mathrm{C} \beta$, and perhaps in lower layer $4 \mathrm{C} \alpha$, nonoriented cells predominate and oriented ones are rarely encountered.

Contrast sensitivity. In Figures $4 C$ and $5 C$ we have plotted contrast threshold as a function of electrode distance. As one can see from each reconstruction, the contrast thresholds of nonoriented units increase as the electrode tip progresses more deeply into layer $4 \mathrm{C}$. This trend is apparent for both penetrations even though the one illustrated in Figure 4 did not encounter nonoriented units until the electrode tip had entered the middle of layer $4 \mathrm{C} \alpha$. Due to the obliqueness of each electrode penetration there is some uncertainty as to whether units recorded from the middle of layer $4 \mathrm{C}$ correspond to the $\alpha$ or to the $\beta$ subdivisions. By excluding these middle units from consideration, we see (Fig. $5 \mathrm{C}$ ) that the mean contrast threshold of the first units $(0.16 \pm 0.02)$ is less, by a factor of 3.5 , than that of the last units $(0.56 \pm$ 0.01 ). In Figure $4 C$ we see a similar but less pronounced (2-fold) difference between the contrast thresholds of units recorded at the beginning and at the end of the penetration. The different ratios may derive from the fact that in one penetration (i.e., Fig. 5) nonoriented units were encountered at a higher level in layer $4 \mathrm{C} \alpha$ than they were for the other (i.e., Fig. 4).

From Figure $5 C$, where we have plotted contrast thresholds for units recorded above and below layer $4 \mathrm{C}$, it is evident that the thresholds of oriented units recorded in layer 4B are as low as those of cells recorded in layer $4 \mathrm{C} \alpha-$ a finding that agrees with the observation (Lund, 1973) that much of the afferent input to layer $4 B$ derives from neurons in layer $4 \mathrm{C} \alpha$. In lamina $4 \mathrm{~A}$, which receives a direct parvocellular input and an indirect magnocellular one (via $4 \mathrm{C} \alpha$ ), we find units with both high and low contrast thresholds.

All of the units recorded in layer $4 \mathrm{C} \alpha$ displayed responses to colored stimuli that can only be described as broad band; accordingly, these cells reflect their source of input from neurons in the magnocellular laminae of the IGN. However, given the color-selective properties of most parvocellular geniculate neurons, we were sur- 


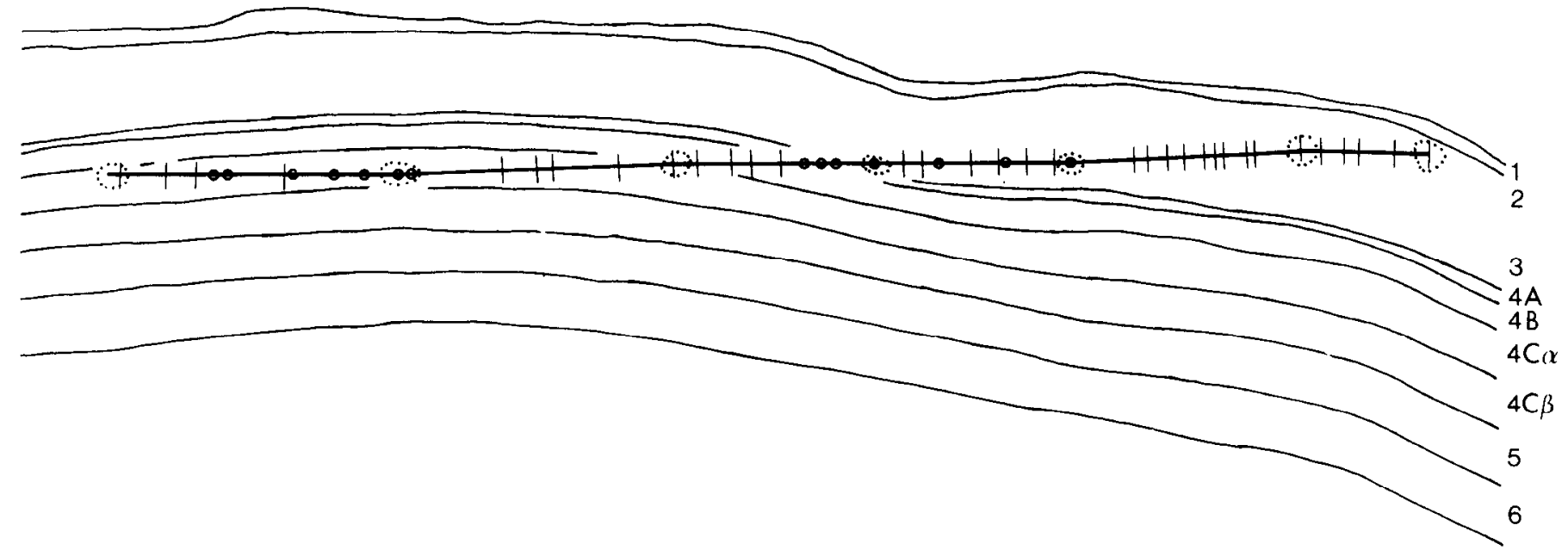

Figure 3. This electrode track was reconstructed from lesions that were recovered from eight serial sections of striate cortex; accordingly, photomicrographs are not presented. Lesions are indicated by small dotted circles, and the laminar boundaries are drawn from tissue sections that were reacted for cytochrome oxidase. During the course of this penetration, the electrode tip traveled through layer $4 \mathrm{C} \alpha$ for a distance of at least $3 \mathrm{~mm}$. Interestingly, during the course of this penetration, unbroken sequences of both orientationally selective and non-orientationally selective units were encountered. Accordingly, we believe that the transition zone between oriented and nonoriented units, which is nevertheless quite sharp, may actually occur at variable depths relative to the upper boundary of the cytochrome-rich zone that we use to define lamina $4 \mathrm{C}$. One possibility, elaborated in the "Discussion," is that clusters of non-orientationally selective cells may interdigitate with clusters of orientationally selective ones that protrude downward from layer $4 \mathrm{~B}$ above.

prised to find that few of the units recorded in layers $4 \mathrm{~A}$ and $4 \mathrm{C} \beta$ could be described as "color selective;" most responded exceptionally well to white light. When tested with individual component colors (e.g., red, green, or blue), however, we frequently found responses to all but one of these three colors. For example, an ON-center cell that responded strongly to a red or a green disk did not respond at all to a blue disk. Another nonoriented unit, which was localized later to $4 \mathrm{C} \beta$, responded well to red, green, or blue disks in its center; but this response was only antagonized by blue or green light in the surround. It is our impression that traditional color opponent responses were encountered somewhat more frequently in layer $4 \mathrm{~A}$ than they were in layer $4 \mathrm{C} \beta$; however, many more units must be recorded, in both $4 \mathrm{~A}$ and $4 \mathrm{C} \beta$, before accurate percentages can be stated.

Receptive field size. As noted under "Materials and Methods," our measurements of receptive field size relicd on estimates of the minimum response field. In Figure 6 we present post-stimulus time histograms that document the responses of a layer $4 \mathrm{C} \alpha$ cell to narrow light and dark bars that were presented for $0.5 \mathrm{sec}$ at various locations within the minimum response field. The salient points of this figure are: (1) the extremely low spontaneous activity of this unit, typical of layer $4 \mathrm{C}$ cells, which makes it unlikely that this recording derives from an LGN fiber; (2) the absolute refusal of this cell to respond to either the presentation or the cessation of a dark bar, at any position in the receptive field; and (3) the excellent agreement between the limits of the hand-plotted fields and the positions where the presentation of a light bar elicits a response. The agreement between hand- and computer-plotted response zones is evident for all orientations of stimulus; but, for simplicity, we have presented only the responses to a vertical bar.
In Figures $4 B$ and $5 B$ we have plotted receptive field center sizes (vertical diameter of the minimum response field) for each of the two electrode penetrations illustrated in Figures $4 A$ and $5 A$. The approximate positions where the electrode tips crossed the upper and the lower boundaries of layers $4 \mathrm{C} \alpha$ and $4 \mathrm{C} \beta$ are indicated by dotted lines, and in Figure 5 the position of layer $4 \mathrm{~A}$ is indicated as well. As one can see from these figures, the minimum response fields are larger, by a factor of 2 , in the upper half of layer $4 \mathrm{C}$ than they are in the lower half. From Figure 5, where we have plotted minimum response field sizes for units recorded in layers $4 \mathrm{~A}, 4 \mathrm{~B}$, and upper 5 , it is apparent that field sizes increase suddenly at the $4 \mathrm{~A} /$ $4 \mathrm{~B}$ border, decrease at the $4 \mathrm{~B} / 4 \mathrm{C} \alpha$ border, and decrease again as the electrode passes more deeply into layer $4 \mathrm{C} \beta$. In layer 5 , the minimum response fields again become quite large.

Tangential organization of $4 C$ receptive fields. As noted under "Materials and Methods," all of our electrode penetrations ran in the parasagittal plane. This means, from the maps of Hubel and Freeman (1977) and Tootell et al. (1982), that our highly angled penetrations, traversing the representation of the horizontal meridian from anterior to posterior, correspond primarily to an upward movement in the visual field. In Figure $4, D$ and $E$, we have plotted the elevations and azimuths, respectively, for 33 nonoriented units that we encountered during one long $(2.5 \mathrm{~mm})$ traverse through layer $4 \mathrm{C}$. During the course of this penetration we crossed ocular dominance boundaries eight times, and in spite of the sudden jumps that occur at each boundary, the receptive field elevations of successively recorded cells change in a predictable and orderly fashion whereas azimuths remain nearly constant. From the reconstruction in Figure $4 D$ one can see that the orderliness of this progression is just as 

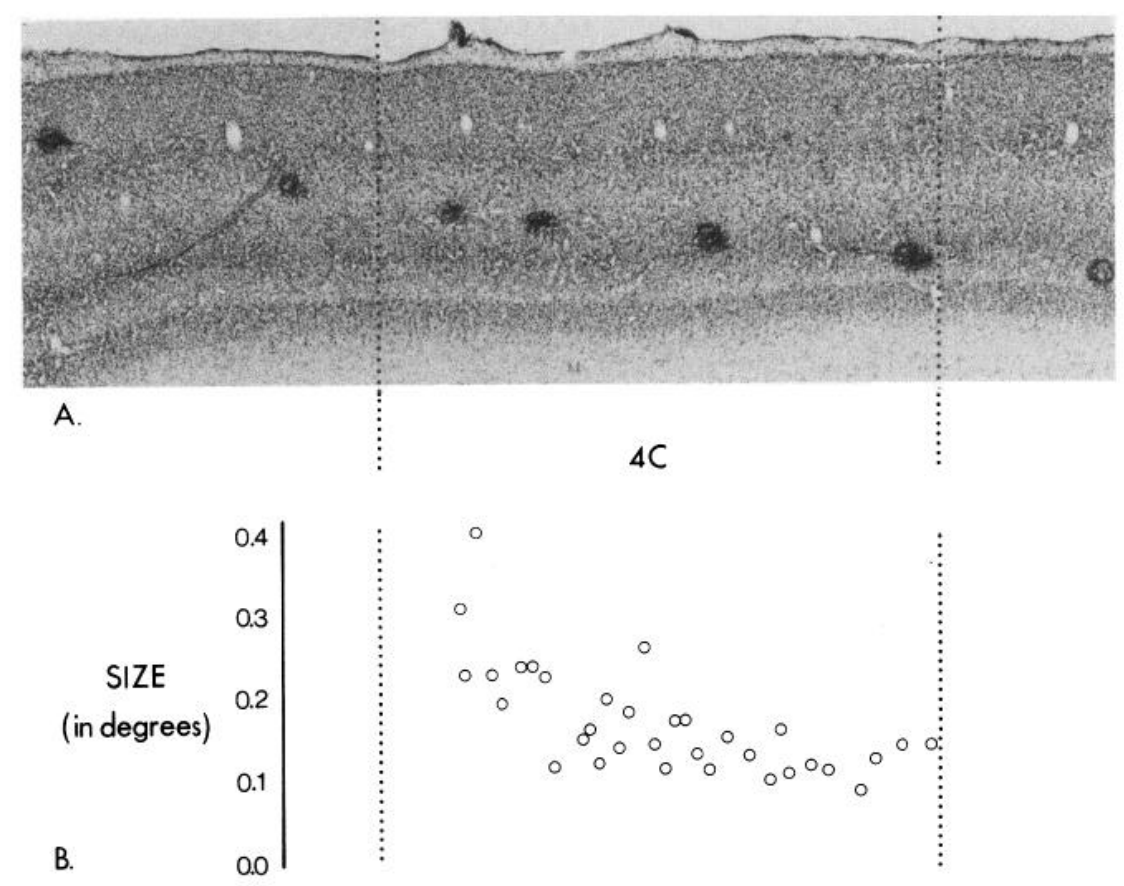

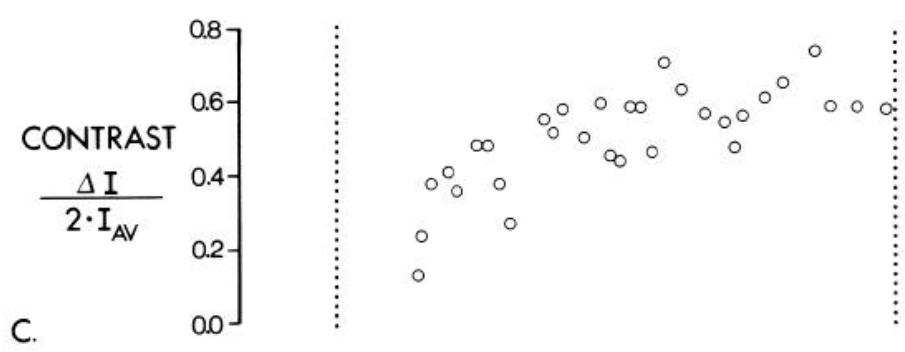
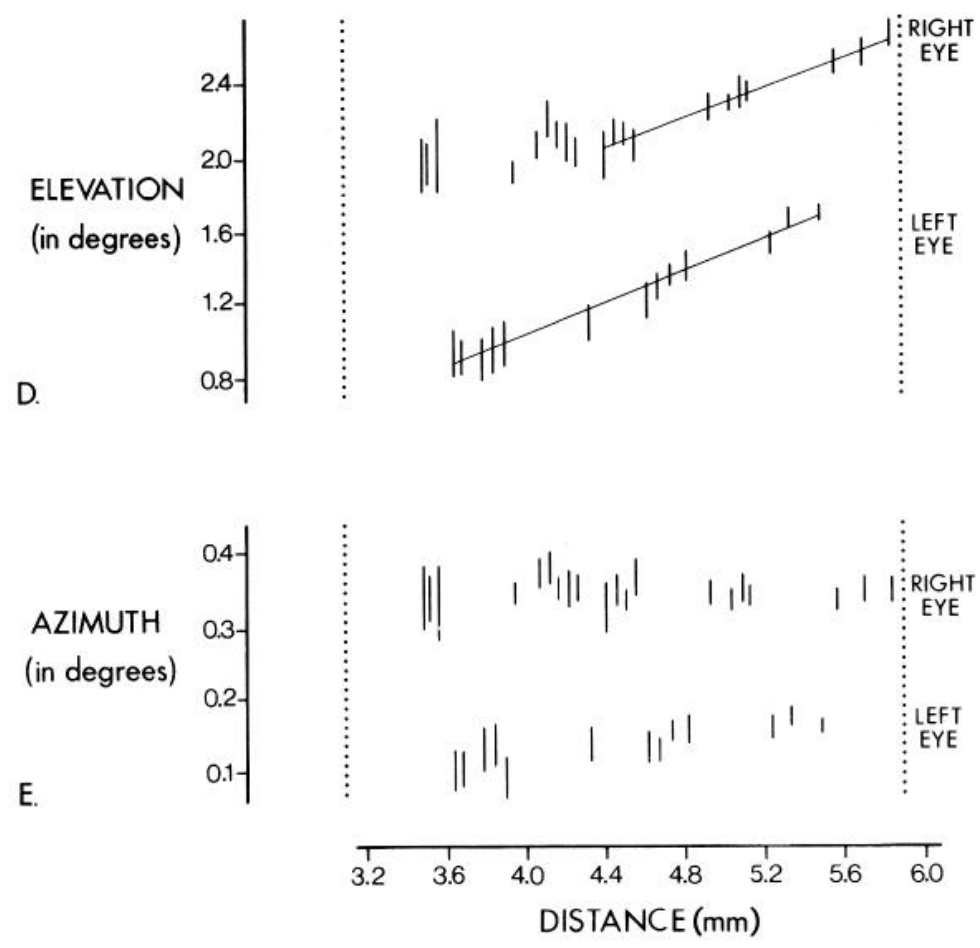

Figure 4 
apparent at the beginning of the traverse through layer $4 \mathrm{C}$ as it is at the end.

In Figure $5 D$ one sees a similar reconstruction, only in this case the units recorded both before and after the traverse through layer $4 \mathrm{C}$ are presented for comparison. Orderliness in the vertical progression is again just as apparent at the beginning of the traverse through layer $4 \mathrm{C}$ as it is at the end. A linear regression analysis confined to the passage through layer $4 \mathrm{C}$ reveals a correlation coefficient of 0.92 between electrode position and receptive field elevation for one eye (Fig. 5D, upper plots) and 0.99 for the other eye (Fig. $5 D$, lower plots). From the four units that we recorded during the short passage through layer $4 \mathrm{~A}$ we see, in addition, that the tight retinotopic organization of layer $4 \mathrm{C}$ may apply to layer $4 \mathrm{~A}$ as well. However, this certainly is not the case for units recorded in layers $4 \mathrm{~B}$ and 5 , where the minimum response fields not only appear randomly organized but have centers which display a marked vertical offset with respect to the linear regression line drawn through the fields of the nonoriented units in layer $4 \mathrm{C}$.

Layer $4 \mathrm{~A}$. As noted earlier, there are two prominent levels in layer 4 where an electrode encounters nonoriented cells. Although layer $4 \mathrm{~A}$ is thinner than $4 \mathrm{C}$ and contains fewer cells, it nevertheless appears to be populated mostly by monocularly driven units that lack orientation selectivity. As one can see from Figure $5 B$, minimum response field sizes and contrast thresholds approximate those found in layer $4 \mathrm{C}$.

Because of the small, largely nonoriented, minimum response fields that we determine for units in layer $4 \mathrm{~A}$, it is tempting to speculate that this layer, like $4 \mathrm{C}$, might be retinotopically mapped on a small scale. One certainly gains this impression from the four units from layer $4 \mathrm{~A}$ that are shown on the left side of Figure 5. Due to the thinness of this lamina, it is difficult to make long tangential penetrations through it; however, in one case, we managed to traverse it for $1 \mathrm{~mm}$. This particular penetration is reconstructed in Figure 7A. In Figure 7, $B$ and $C$, we have plotted the elevations and azimuths of the minimum response fields that we encountered. We crossed ocular dominance boundaries three times and in the process recorded from 13 units, 10 of which lacked orientation selectivity and were monocular. From the gradual shift in receptive field elevation that appears in Figure $7 B$, it is apparent that layer $4 \mathrm{~A}$ is retinotopically mapped on a relatively small scale, although the precision may not be as great as that found in layer $4 \mathrm{C}$. The lower density of recorded cells - due most probably to the lower packing density of cells in this layer-makes it difficult to tell. The three solid circles in Figure $7 A$ represent recordings from nonoriented units that responded best to light of a single color.

\section{Discussion}

These results indicate that the three geniculorecipient zones of layer 4 are each characterized by an orderly arrangement of monocularly driven cells with nonoriented receptive fields. The cells recorded within each zone have small minimum response fields and many of their physiological properties are consistent with those of their afferent inputs. Cells in layers $4 \mathrm{~A}$ and $4 \mathrm{C} \beta$, which derive input primarily from cells in the parvocellular LGN laminae, display some color selectivity, and the cells in $4 \mathrm{C} \beta$ all have high thresholds to luminance contrast. On the other hand, cells in layer $4 \mathrm{C} \alpha$, which derive their input from the magnocellular LGN laminae, have larger minimum response fields and display much lower thresholds to luminance contrast.

In our sample of 171 nonoriented units, recorded during the course of 13 highly tangential electrode penetrations, we observe an abrupt transition at the top of layer $4 \mathrm{C}$ where units having orientational selectivity and large binocular receptive fields suddenly give way to monocularly driven ones that lack orientation selectivity and that display extremely small receptive fields. Due to their low spontaneous activity, one can be sure that these are not LGN afferents. Furthermore, on the basis of their

Figure 4. A, Photomicrograph of a Nissl section from which we recovered eight lesions (first lesion not shown) that were made during the course of a single electrode penetration, in the sagittal plane, through the opercular region of striate cortex. The dotted lines delimit the part of this penetration that we believe was made within the cytochrome-rich zone of layer $4 \mathrm{C}$. Between the fourth and the seventh lesions, we recorded from an unbroken sequence of 33 nonoriented cells whose salient characteristics are plotted below in $B$ to $E$. $B$, As this plot makes clear, the minimum response fields of units recorded at the beginning of the traverse through layer $4 \mathrm{C}$ were larger than those of units recorded toward the end of this traverse. $C$, In a fashion reciprocal to the decrease in receptive field size seen in $A$, this plot illustrates the increase in luminance contrast threshold that is seen for units recorded at successively greater depths in layer 4C. $D$ and $E$, In these figures we have plotted the elevations and azimuths of the minimum response fields of units recorded during the traverse through layer $4 \mathrm{C}$. In order to give a realistic impression of the visuotopic information that is being represented, we have made the length of each vertical line correspond to the vertical visual angle which the minimum response field subtends in visual space. Actual displacements in azimuth and elevation are relative, and the receptive fields of the right and left eyes are displayed vertically offset from one another in order to facilitate analysis. Since the electrode penetration was made from anterior to posterior, in the sagittal plane, there is a net increase in elevation during the course of this penetration, whereas azimuthal values remain relatively constant. Note that during both the earlier and the later parts of the penetration, there is a net upward drift that may be discerned within the width of a single ocular dominance column, but that the step size, in visual angle, is small in comparison with the angle subtended by the minimum response field. Linear regression lines have been drawn through the receptive field plots for the right and left eyes (correlation coefficients of 0.92 and 0.99 for the right and left eyes respectively). The slopes of these lines indicate an inverse magnification factor of $0.49^{\circ}$ (visual angle) per millimeter of cortex traversed. Assuming a minimum response field of $0.25^{\circ}$ for a unit in layer $4 \mathrm{C} \alpha$ (derived by averaging the diameters of the first nine units), we see that our electrode must travel laterally for approximately $660 \mu \mathrm{m}$ before the recorded units sample a totally different, and non-overlapping, part of visual space. Applying a similar calculation to the minimum response fields of layer $4 \mathrm{C} \beta$ (mean receptive field size of $0.12^{\circ}$ ), we arrive at a distance of $290 \mu \mathrm{m}$ for this part of layer $4 \mathrm{C}$. Both values correspond closely, within a factor of 2 , to the known arborizational distances of single LGN afferents to the respective subdivisions of lamina $4 \mathrm{C}$. 
A.

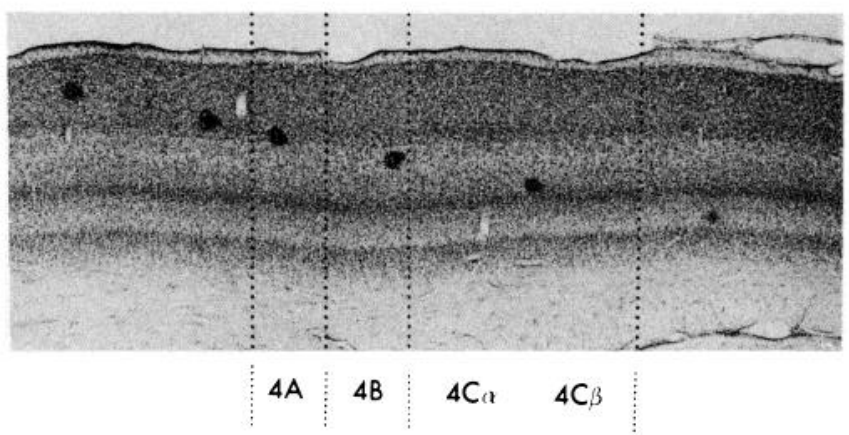

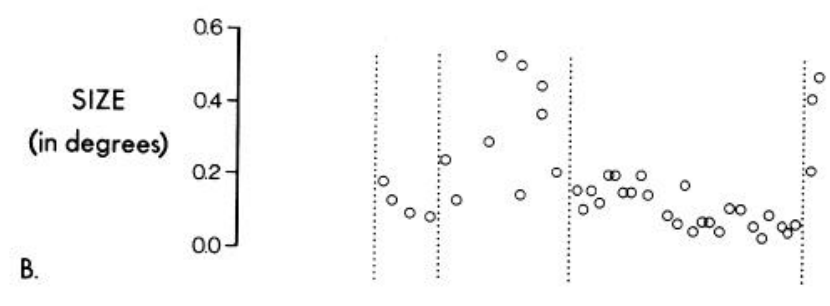

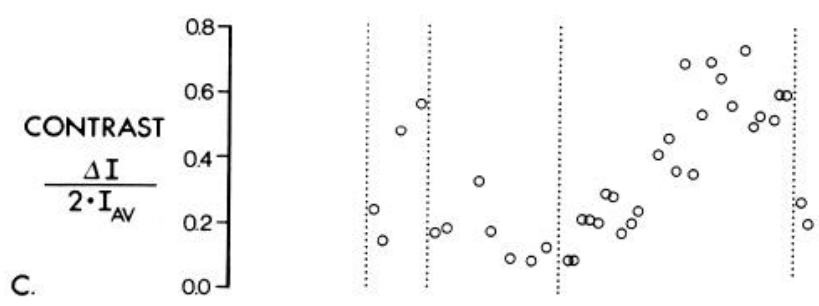

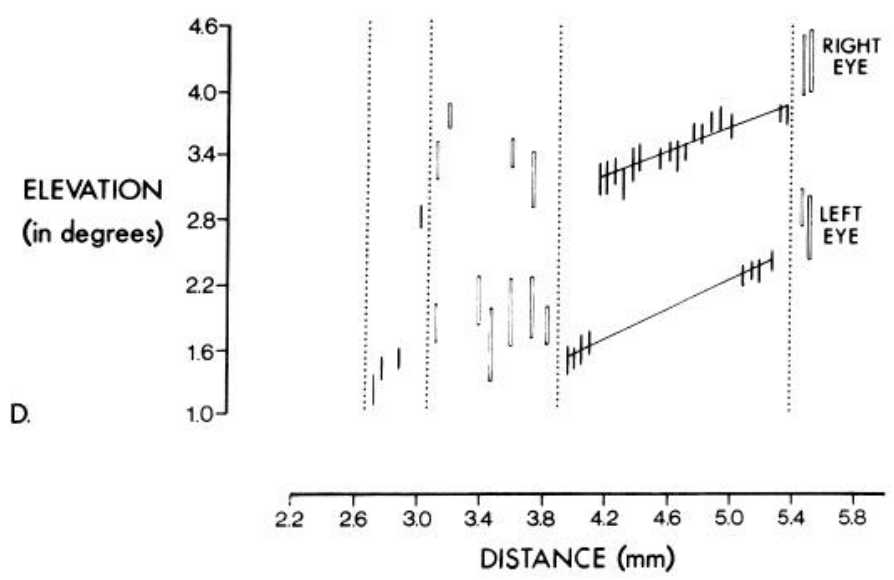

Figure 5. A, Reconstruction of electrode track shown in Figure 1. During the course of this penetration we recorded from 36 units within layer 4, 29 of which lacked orientation selectively and were recorded in either layer 4A or layer 4C. As noted in Figure 1, the first nonoriented cells, with low contrast thresholds, were recorded soon after our electrode tip penetrated layer $4 \mathrm{C} \alpha . B$, In this diagram, the vertical angle subtended by each minimum response field is plotted as a function of electrode distance. In agreement with the observations of Hubel and Wiesel (1977), the units recorded from layer 4C are among the smallest to be found in striate cortex. Compare, for example, the sizes determined for cells in layer $4 \mathrm{C}$ with those determined for cells in layers $4 \mathrm{~B}$ and 5 . Interestingly, the nonoriented cells recorded from layer $4 \mathrm{~A}$ are monocularly driven and have minimum response fields of approximately the same dimensions as those determined for cells in layer $4 \mathrm{C}$. $C$, Contrast thresholds are plotted as a function of depth in layer 4. Note that, in agreement with their different sources of thalamic input, the cells in layer $4 \mathrm{C} \alpha$ have much lower thresholds to luminance contrast than do the cells recorded in layer $4 \mathrm{C} \beta$. Note also that the cells recorded in layers $4 \mathrm{~B}$ and 5 have contrast thresholds that are just as low as those determined for layer $4 \mathrm{C} \alpha-\mathrm{a}$ finding which implies that cells in laminae $4 \mathrm{~B}$ and 5 derive input from cells in layer $4 \mathrm{C} \alpha . D$, Receptive field elevation (in degrees) plotted as a function of electrode track distance. As in Figure $4 D$, note the neat progression in receptive field position as the electrode traverses layer 4C. Orderliness is apparent both at the beginning and at the end of the progression. Correlation coefficients for the linear 
low contrast thresholds, we have little doubt that the uppermost of these nonoriented cells receive a magnocellular input. Nevertheless, we find that the physiologically determined point of transition, between oriented and nonoriented cells, does not always correspond to the upper boundary of lamina $4 \mathrm{C} \alpha$, as we have chosen to define it (from the presence of rich cytochrome oxidase activity), and usually occurs somewhat below. For some penetrations (Fig. 2) the transition does not occur until the electrode tip has penetrated into $4 \mathrm{C} \beta$, and for one, which remains utterly tangential through at least $3 \mathrm{~mm}$ of lamina $4 \mathrm{C} \alpha$, we observed sequential clumps of oriented and non-oriented units.

Taken together, these observations imply that the physiologically determined point of transition between oriented and nonoriented cells, although always abrupt, does not lie in rigid association with the cytochrome oxidase boundary. Accordingly, these results may explain previous conflicting reports about the location of nonoriented units in various parts of lamina $4 \mathrm{C}$ (Hubel and Wiesel, 1968, 1977; Bullier and Henry, 1980; Livingstone and Hubel, 1984). Although the reason for the observed variability is not clear, it is conceivable that the orientationally selective cells of layer $4 \mathrm{~B}$, which are frequently binocular, intrude to some variable (and possibly patchy) extent into layer $4 \mathrm{C} \alpha$ (in fact, many of the oriented units that we observed in layer $4 \mathrm{C} \alpha$ displayed binocular receptive fields). It is probable that these oriented cells receive direct magnocellular input (Bullier and Henry, 1980). With this possibility in mind it is interesting to note that injections of horseradish peroxidase (HRP) into layer 4 reveal a regular and repeating pattern of intrinsic lateral connections in layer 4B that extend downward into layer $4 \mathrm{C} \alpha$ (Rockland and Lund, 1983). Since a similar set of patchy connections appears (following HRP injections) in layers 2 and 3 where oriented cells predominate (Hubel and Wiesel, 1977), it is possible that patchy interconnections characterize laminae where orientation specificity is present. If so, the patches of oriented cells that we record in layer $4 \mathrm{C} \alpha$ may lie within such zones.

Contrast sensitivity. Zones of layer 4 that receive input from the magno- and parvocellular laminae of the LGN are most consistently distinguished from one another on the basis of luminance contrast thresholds. Cells in layer $4 \mathrm{C} \alpha$, which receive a direct magnocellular input, display low thresholds whereas cells in layer $4 \mathrm{C} \beta$, which receive a parvocellular input, display high thresholds. In layer $4 \mathrm{~A}$ we observed cells with both high and low thresholds to luminance contrast and, accordingly, we believe that this layer receives a contribution from both the parvoand the magnocellular divisions of the LGN. Although a direct parvocellular input has been established (Hubel and Wiesel, 1972; Hendrickson et al., 1978), there is no evidence for a direct magnocellular input. However, it is possible that the pyramidal neurons of layer $4 \mathrm{~A}$, which send their basal dendrites down into layer $4 \mathrm{~B}$ (Lund, 1973), receive an indirect magnocellular input from re- lays in layer $4 \mathrm{C} \alpha$. If so, then future intracellular HRP experiments should find differences in the contrast thresholds of the stellate and pyramidal cells of layer $4 \mathrm{~A}$.

Just as units with low contrast thresholds predominate in layers $4 \mathrm{~B}$ and $4 \mathrm{C} \alpha$, cells with pronounced spectral selectivities occur only in layers $4 \mathrm{~A}$ and $4 \mathrm{C} \beta$ (for layer 4). Such cells are rare, however, and certainly less prominent than they are in the parvocellular laminae of the LGN (Wiesel and Hubel, 1966; Dreher et al., 1977; Schiller and Malpeli, 1978). There are several possible reasons for this. One is that our electrode blended the responses of several cells-cells that recorded individually might appear color selective. If this is the case, it follows that cells with different color selectivities must be closely intertwined, and in order for each cell in $4 \mathrm{C} \beta$ to retain color selectivity, it must extract it from many (20 to 40; see below) overlapping parvocellular afferents. It seems unlikely, though, that incomplete isolation can explain the low proportion of color-selective units that we observe. Bullier and Henry (1980), who took great pains to isolate single units in layer $4 \mathrm{C} \beta$, reported a similarly low proportion. In addition, Livingstone and Hubel (1984), though they find a higher proportion of color opponent units in layer $4 \mathrm{C} \beta$, still find that this proportion is lower than that observed in the LGN. In view of the great divergence in cell numbers that occurs between the LGN and layer $4 \mathrm{C}$-somewhere between 25 and 100 potential postsynaptic cells for each LGN afferent (O'Kusky and Colonnier, 1982), it is possible that spectrally selective responses can be relayed directly to some cells, in a 1:1 fashion, and these cells would still comprise only a small proportion of those sampled in layer $4 \mathrm{C} \beta$. In layer $4 \mathrm{~A}$, where the densities of both arborizing afferent axons and postsynaptic cells are lower, the chances for relaying spectrally pure information might be better.

Retinotopic organization of layer $4 C$. In layers $4 \mathrm{~A}$ and $4 \mathrm{C}$, receptive field positions fall into a definite retinotopic order that is apparent within the width of even a single ocular dominance column. In layer $4 \mathrm{C}$ the phenomenon is particularly striking because the cells in this layer are densely packed and the distances between successively sampled cells are short. Given the fact that magnocellular axons in layer $4 \mathrm{C} \alpha$ cover a greater area than parvocellular axons in layer $4 \mathrm{C} \beta$, it is surprising that retinotopic order is not more pronounced in the $\beta$ subdivision than it is in the $\alpha$ subdivision. The fact that it is not suggests that the spreads of afferent axons have little to do with the precision of a retinotopic map. In both $4 \mathrm{C} \beta$ and $4 \mathrm{C} \alpha$, retinotopically precise shifts are discernible within the dimensions of single afferent fibers.

One possible explanation for this lack of correlation between the terminal field sizes of afferent axons and the precision of retinotopic mapping involves a re-evaluation of the role played by LGN axons in driving postsynaptic cells in layer $4 \mathrm{C}$. While one might like to

regression lines drawn through the right and left eye plots are 0.97 and 0.99 , respectively. Note that during the brief traverse through lamina $4 \mathrm{~A}$ there is a hint of retinotopic mapping (for the left eye) as well. Open bars indicate units that were determined to be orientationally selective. Note that the linear regression lines drawn through the layer $4 \mathrm{C}$ units do not intersect the geometric centers of the units in layers $4 \mathrm{~B}$ and 5 . 

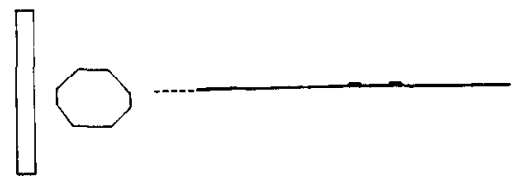<smiles>C1CC2CCC1CC2</smiles>
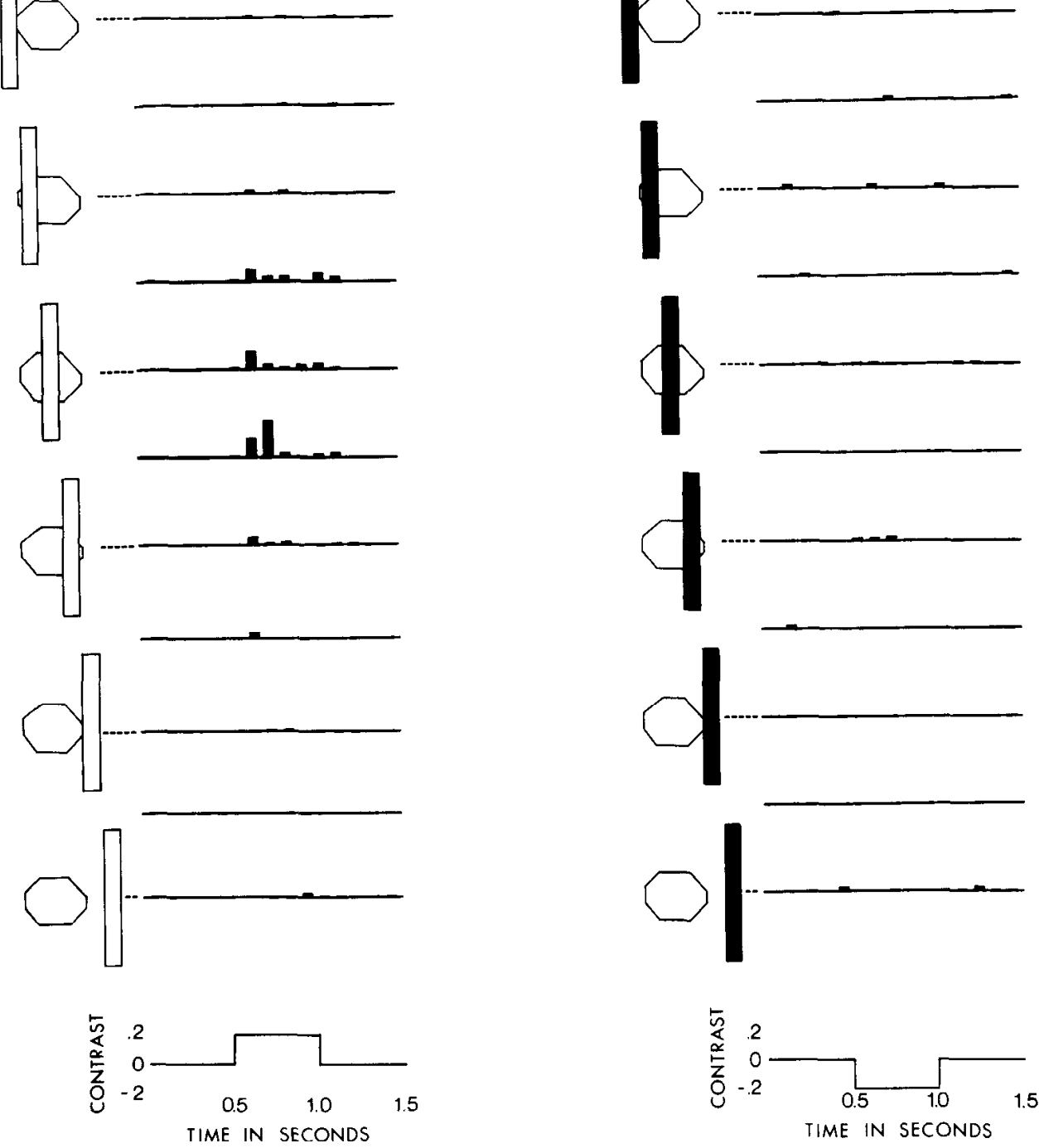

Figure 6. This figure depicts the responses of a single layer $4 \mathrm{C} \alpha$ cell to a bar flashed for $0.5 \mathrm{sec}$ at various positions in its receptive field. The illustrations to the left of alternate post-stimulus time histograms illustrate the position of the bar relative to the handplotted minimum response field during each trial. Stimulus presentation occurred in a pseudorandom sequence wherein different bar positions and contrasts were interleaved with one another. Note the very low spontaneous activity of this cell and the excellent correspondence between the hand-plotted minimum response field and the positions where computer-controlled test bars elicit a response. Interestingly, the cell responds only to the presentation of a light bar; presentations and cessations of dark bars, at all positions, go unnoticed. 


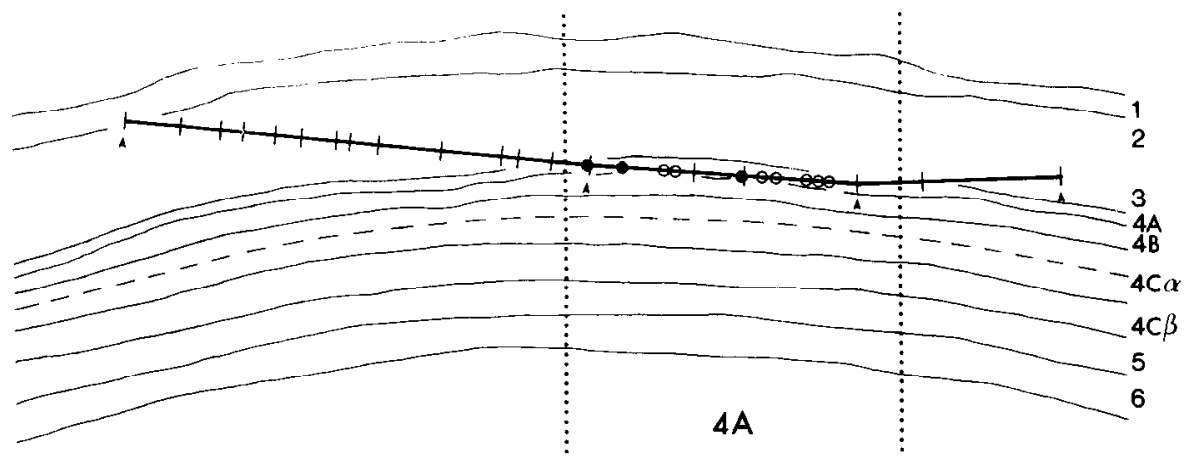

A.

B.

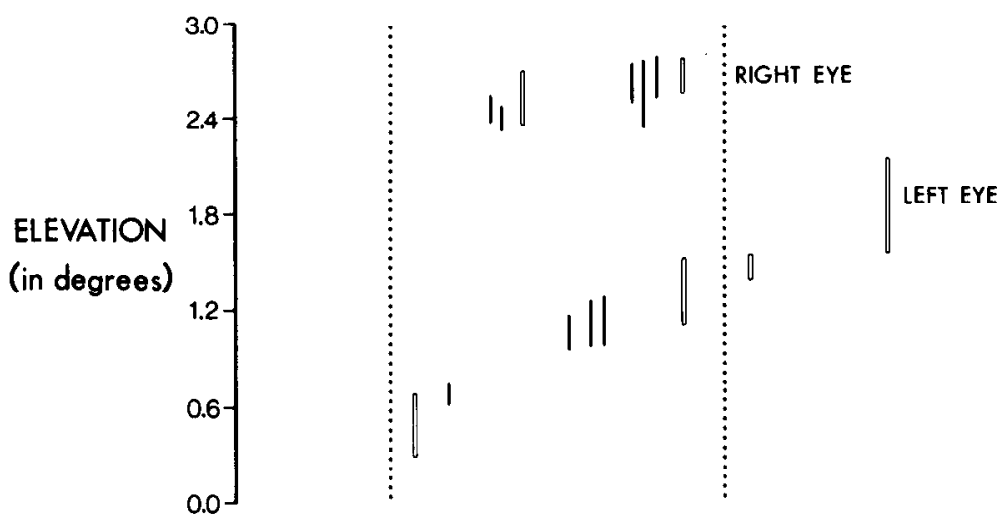

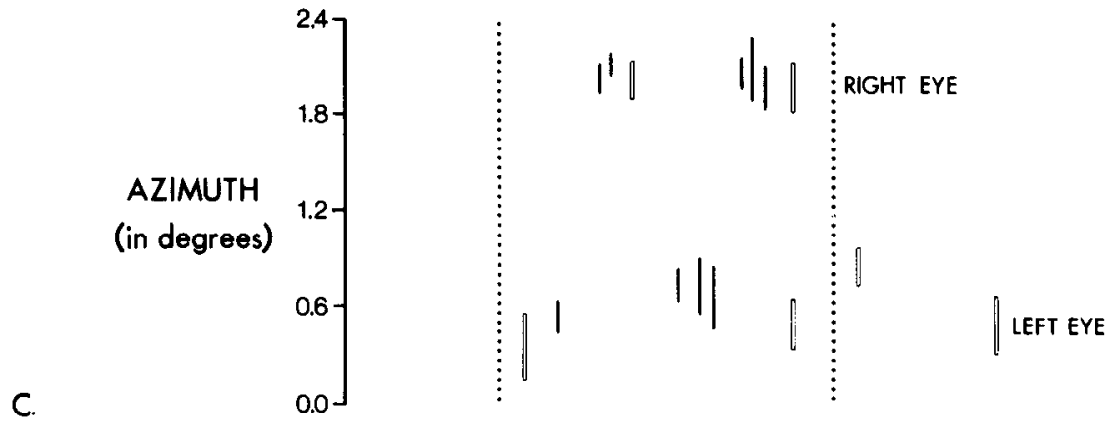

$\begin{array}{llllllll}2.6 & 2.8 & 3.0 & 3.2 & 3.4 & 3.6 & 3.8 & 4.0 \\ & & & & \text { DISTANCE (mm) }\end{array}$

Figure 7. A, During the course of one electrode penetration we managed to skewer lamina $4 \mathrm{~A}$ for a distance of $1 \mathrm{~mm}$. We crossed ocular dominance boundaries four times and recorded from 13 cells, 10 of which lacked orientation selectivity and responded monocularly to visual stimulation. In $B$ one can see a suggestion that the visual fields are retinotopically mapped (as for lamina $4 \mathrm{C}$ ), although the density of recorded cells is not as great as that seen in lamina 4C. From the presence of monocularly driven, nonoriented cells in the lamina, as well as the suggestion of an orderly retinotopic arrangement, it seems plausible that this type of organization typifies zones of pronounced geniculate input. 
think, for simplicity's sake, that individual LGN afferents terminate in an infinitely discrete fashion, each exciting only a few $1 \mathrm{C}$ neurons, it seems more likely that these afferents provide a broad, overlapping and slightly diffuse pattern of activity out of which the population of postsynaptic cells somehow manages to extract a precise map. If this is the case, then the precision of mapping might relate more directly to the arrangement and homogeneity of dendritic fields than to the terminal field sizes of afferent axons. The observed uniformity of map. ping precision between $4 \mathrm{C} \alpha$ and $4 \mathrm{C} \beta$ would then coincide with the known similarity between the dendritic spreads of cells in these two subdivisions (Lund, 1973). The greater spreads of afferent axons in $4 \mathrm{C} \alpha$ might simply imply greater overlap, and this increased overlap would then generate large minimum response fields for the cells lying postsynaptic without effecting the orderliness of receptive field arrangement.

By combining the diameters of minimum response fields with local magnification factors (known from the slope of the linear regression lines in Figs. 4 and 5), it is possible to calculate how far laterally one must move in layer $4 \mathrm{C}$ before entering a new and non-overlapping part of the visual field. When Hubel and Wiesel (1974) made an analogous estimate for the cells in all layers of macaque striate cortex, they concluded that a lateral displacement of 2 to $3 \mathrm{~mm}$ was required before the representation moved into a totally new and non-overlapping part of the visual field--a distance which they noted corresponds to two to three complete sets of orientation or ocular dominance columns. If we restrict our attention to layer $4 \mathrm{C} \alpha$, where the mean minimum response field size is only $0.25^{\circ}$, we see from Figure $4 D$ that $600 \mu \mathrm{m}$ of lateral displacement is required to move into a new part of the visual field. In layer $4 \mathrm{C} \beta$, where the receptive fields are smaller, the necessary displacement reduces to $290 \mu \mathrm{m}$. These distances are intriguing since they correspond, within a factor of 2 , to the known spreads of single arborizing LGN afferents in both the $\alpha$ and the $\beta$ subdivisions of layer 4C (Blasdel and Lund, 1983). One might infer from these calculations that two $4 \mathrm{C}$ cells, having separate and non-overlapping minimum response fields, must be separated by enough physical distance to ensure that they are not contacted by the same LGN afferent.

The question of how the information carried by individual geniculate fibers becomes altered in the transfer to postsynaptic $4 \mathrm{C}$ neurons remains to be answered. If we restrict our attention to layer $4 \mathrm{C} \beta$, our results are consistent with the notion that each cell receives input from all of the parvocellular afferents that arborize within its dendritic field. This notion is strengthened by the observation that color opponency, so prevalent among parvocellular LGN cells, is rarely observed among the cells in layer $4 \mathrm{C} \beta$. If we assume that one hemisphere of macaque striate cortex has a surface area of $1,300 \mathrm{~mm}^{2}$ and that there are 800,000 parvocellular afferents $\left(0^{\prime} \mathrm{Ku}-\right.$ sky and Colonnier, 1982), each covering $0.065 \mathrm{~mm}^{2}$ of cortical surface (Blasdel and Lund, 1983), then, conservatively, one might expect between 20 and 40 parvocellular afferents to overlap at any particular point in layer $4 \mathrm{C}$, and this should also be the number of parvocellular afferents that are able to contact a single postsynaptic cell. The number is larger if we allow for dendritic spread.

Such a convergence must certainly serve a purpose more profound than the simple mixing of afferent inputs. There must be features elaborated that have not yet been made explicit in the responses of LGN neurons. If we assume that there are 800,000 parvocellular afferents, and 27,000,000 potential targets (O'Kusky and Colonnicr, 1982), we have a divergence of $1: 30$, which should allow any number of properties to be elaborated. Barlow (1980) has suggested that the cells of layer 4C might interpolate among their inputs to achieve a topographical precision which is greater than that found in the retina. In other words, there might be an elaboration of topographical precision. This is not the only possibility, however. Others include contrast and color sensitivity, movement sensitivity, spatial frequency, and so on. At the very least, cells in layer $4 \mathrm{C}$ may elaborate the certainty with which they detect an edge. However, before we can achieve further insights into the transformations that occur, it will be necessary to make more precise comparisons between the receptive field properties of individual LGN cells and those of individual, homotopically located $4 \mathrm{C}$ cells that receive their input.

\section{References}

Barlow, H. B. (1980) Critical limiting factors in the design of the eye and visual cortex. Proc. R. Soc. Lond. (Biol.) 212: 134.

Barlow, H. B., C. Blakemore, and J. D. Pettigrew (1967) The neural mechanism of bionocular depth discrimination. J. Physiol (Lond.) 19.3: 327-342.

Blasdel, G. G., and J. S. Lund (1982) Physiological and morphological analysis of afferent axons in thalamo-recipient laminae of macaque striate cortex. Soc. Neurosci. Abstr. 8: 705.

Blasdel, G. G., and J. S. Lund (1983) Termination of afferent axons in macaque striate cortex. J. Neurosci. 3: 1389-1413.

Blasdel, G. G., D. E. Mitchell, D. W. Muir, and J. D. Pettigrew (1977) A physiological and behavioural study in cats of the effect of early visual experience with contours of a single orientation. J. Physiol. (Lond.) 277: 615-636.

Blasdel, G. G., D. Fitzpatrick, and J. S. Lund (1983) Physiological and anatomical studies of retinotopic maps in macaque striate cortex. Invest. Ophthalmol. Vis. Sci. 24: 266.

Bullier, J., and G. H. Henry (1980) Ordinal position of afferent input of neurons in monkey striate cortex. J. Comp. Neurol. 193: 913-936.

Chow, K. L., J. S. Blum, and R. A. Blum (1950) Cell ratios in the thalamo-cortical visual system of Macacca mulatta. J. Comp. Neurol. 92: 227-239.

Dow, B. M. (1974) Functional classes of cells and their laminar distribution in monkey visual cortex. J. Neurophysiol. 37: 927-946.

Dreher, B., Y. Fukuda, and R. W. Rodieck (1976) Identification, classification and anatomical segregation of cells with X-like and Y-like properties in the lateral geniculate nucleus of OldWorld primates. J. Physiol. (Lond.) 258: 433-452.

Feldberg, W., and K. Fleischer (1960) Penetration of bromophenol blue from the perfused cerebral ventricals into the brain tissue. J. Physiol. (Lond.) 150: 451-462.

Fitzpatrick, D., K. Itoh, and I. T. Diamond (1983) The laminar organization of the lateral geniculate body and the striate 
cortex in the squirrel monkey (Saimiri sciureus). J. Neurosci. 3: 673-702.

Gouras, P. (1974) Opponent-colour cells in different layers of foveal striate cortex. J. Physiol. (Lond.) 238: 583-602.

Hendrickson, A. E., J. R. Wilson, and M. P. Ogren (1978) The neuroanatomical organizations of pathways between dorsal lateral geniculate nucleus and visual cortex in Old and New World primates. J. Comp. Neurol. 182: 123-136.

Horton, J., and D. H. Hubel (1981) Regular patchy distribution of cytochrome oxidase staining in primary visual cortex of macaque monkey. Nature 292: 762-764.

Hubel, D. H., and D. C. Freeman (1977) Projection into the visual field of ocular dominance columns in macaque monkey. Brain Res. 122: 336-343.

Hubel, D. H., and M. S. Livingstone (1981) Regions of poor orientation tuning coincide with patches of cytochrome oxidase staining in monkey striate cortex. Soc. Neurosci. Abstr. $7: 357$.

Hubel, D. H., and T. N. Wiesel (1962) Receptive fields, binocular interaction and functional architecture of monkey striate cortex. J. Physiol. (Lond.) 195: 106-154.

Hubel, D. H., and T. N. Wiesel (1968) Receptive fields and functional architecture of monkey striate cortex. J. Physiol. (Lond.) 195: 215-243.

Hubel, D. H., and T. N. Wiesel (1972) Laminar and columnar distribution of geniculo-cortical fibers in the macaque monkey. J. Comp. Neurol. 146: 421-450.

Hubel, D. H. and T. N. Wiesel (1973) A re-examination of stereoscopic mechanisms in area 17 of the cat. J. Physiol. (Lond.) 232: 29P-30P.

Hubel, D. H., and T. N. Wiesel (1974) Uniformity of monkey striate cortex: A parallel relationship between field size, scatter and magnification factor. J. Comp. Neurol. 158: 295306.

Hubel, D. H., and T. N. Wiesel (1977) Functional architecture of macaque monkey visual cortex. Proc. R. Soc. Lond. (Biol.) 198: 1-59.

Hubel, D. H., T. N. Wiesel, and S. LeVay (1974) Visual field of representation in layer IVC of monkey striate cortex. In Society for Neuroscience Program and Abstracts, 1974, p. 264, Society for Neuroscience, Bethesda, MD.

Hubel, D. H., T. N. Wiesel, and S. LeVay (1977) Plasticity of ocular dominance columns in monkey striate cortex. Philos. Trans. R. Soc. Lond. (Biol.) 278: 377-409.

Humphrey, A. L., and A. E. Hendrickson (1983) Background and stimulus-induced patterns of high metabolic activity in the visual cortex (area 17) of the squirrel and macaque monkey. J. Neurosci. 3: 345-358.

Lee, B. B., O. D. Creutzfeldt, and A. Elepfandt (1979) The responses of magno- and parvocellular cells of the monkey's lateral geniculate body to moving stimuli. Exp. Brain Res. 35: 547-557.

Lennie, P., and A. Derrington (1981) Spatial contrast sensitivity in the macaque's LGN. Invest. Ophthalmol. Vis. Sci. (Suppl.) 20: 20.

LeVay, S., D. H. Hubel, and T. N. Wiesel (1975) The pattern of ocular dominance columns in macaque visual cortex revealed by a reduced silver stain. J. Comp. Neurol. 159: 559 576.

LeVay, S., T. N. Wiesel, and D. H. Hubel (1980) The development of ocular dominance columns in normal and visually deprived monkeys. J. Comp. Neurol. 191: 1-51.

Livingstone, M. S., and D. H. Hubel (1984) Anatomy and physiology of a color system in the primate visual cortex. J. Neurosci. 4: 309-356.

Lund, J. S. (1973) Organization of neurons in the visual cortex, area 17 , of the monkey (Macaca mulatta). J. Comp. Neurol. 147: 455-496.

Lund, J. S. (1980) Intrinsic organization of the primate visual cortex, area 17, as seen in Golgi preparations. In The Organization of the Cerebral Cortex. Proceedings of a Neuroscience Research Program Colloquium, F. O. Schmitt, F. G. Worden, G. Adelman, and S. G. Dennis, eds., pp. 97-121, MIT Press, Cambridge, MA.

Lund, J. S., and R. G. Boothe (1975) Interlaminar connections and pyramidal neuron organization in the visual cortex, area 17, of the macaque monkey. J. Comp. Neurol. 159: 305-334.

Marrocco, R. T., J. W. McClurkin, and R. A. Young (1982) Spatial summation and conduction latency classification of cells of the lateral geniculate nucleus of macaques. J. Neurosci. 2: 1275-1291.

Michael, C. R. (1978) Color vision mechanisms in monkey straite cortex: Dual-opponent cells with concentric receptive fields. J. Neurophysiol. 41: 572-588.

Mitzdorf, U., and W. Singer (1979) Excitatory synaptic ensemble properties in the visual cortex of the macaque monkey: A current source density analysis of electrically evoked potentials. J. Comp. Neurol. 187: 71-84.

O'Kusky, J., and M. Colonnier (1982) A laminar analysis of the number of neurons, glia, and synapses in the visual cortex (area 17) of adult macaque monkeys. J. Comp. Neurol. 210 . $278-290$.

Rockland, K. S., and J. S. Lund (1983) Intrinsic laminar lattice connections in primate visual cortex. J. Comp. Neurol. 216: 303-318.

Schiller, P. H., and J. G. Malpeli (1978) Functional specificity of lateral geniculate nucleus laminae of the rhesus monkey. J. Neurophysiol. 41: 788-797.

Schiller, P. H., B. I. Finlay, and S. F. Volman (1976) Quantitative studies of single cell properties in monkey striate cortex. I. Spatiotemporal organization of receptive fields. J. Neurophysiol. 39: 1288-1319.

Shapley, R., E. Kaplan, and R. Soodak (1981) Spatial summation and contrast sensitivity of $\mathrm{X}$ and $\mathrm{Y}$ cells in the lateral geniculate nucleus of the macaque. Nature 292: 543-545.

Sherman, S. M., J. R. Wilson, J. H. Kass, and S. V. Webb (1976) X-and Y-cells in the dorsal lateral geniculate nucleus of the owl monkey (Aotus trivirgatus). Science 192: 475-477.

Tigges, J., M. Tigges, and A. A. Perrachio (1977) Complementary laminar terminations of afferents to area 17 originating in area 18 and in the lateral geniculate nucleus in squirrel monkey (Saimiri). J. Comp. Neurol. 176: 87-100.

Wiesel, T. N., and D. H. Hubel (1966) Spatial and chromatic interactions in the lateral geniculate body of the rhesus monkey. J. Neurophysiol. 29: 1115-1156.

Wolbarsht, M. L., E. F. MacNichol and H. G. Wagner (1960) Glass insulated platinum microelectrode. Science 132: 13091310.

Wong-Riley, M. (1979) Changes in the visual system of monocularly sutured or enucleated cats demonstrable with cytochrome oxidase histochemistry. Brain Res. 171: 11-28. 